\section{Programa Saúde da Família: supervisão ou "convisão"? \\ Estudo de caso em município de médio porte}

\author{
The Family Health Program: \\ supervision or "shared vision"? \\ A case study in a medium-sized Brazilian city
}

\author{
1 Faculdade de Medicina \\ de Teresópolis, Fundação \\ Educacional Serra dos \\ Órgãos, Teresópolis, Brasil. \\ 2 Escola Nacional de Saúde \\ Pública, Fundação Oswaldo \\ Cruz, Rio de Janeiro, Brasil. \\ Correspondência \\ Cláudia da Costa Leite Reis \\ Faculdade de Medicina \\ de Teresópolis, Fundação \\ Educacional Serra dos \\ Órgãos. Rua Guaporé 175 , \\ Teresópolis, $R J$ \\ 25964-000, Brasil. \\ crody.reis@brfree.com.br
}

\begin{abstract}
This study discusses supervision of the Family Health Program (FHP) in Teresópolis Rio de Janeiro State, Brazil, based on a qualitative case study approach. Considering that supervision is an important tool in health programs management,five main objectives were achieved:analysis of supervisory activities, description of characteristics and working patterns, outlining of FHP supervisor profiles, and identification of subjective factors that could interfere in the supervision process. Finally, supervision was considered as an essential step in program organization and implementation. Information sources were interviews with program supervisors and staff members, observation, and document search. The aim was to identify perceptions, attitudes, values, and tendencies concerning supervision. Thanks to this study, it was possible to discuss participatory supervision in the health area, by providing a more level relationship between participants and their effect on health practices, fostering the autonomy of various players in the supervisory process and fostering program support, both suitable for changes in the Brazilian health care model.
\end{abstract}

Family Health Program; Supervision; Health Care
Cláudia da Costa Leite Reis 1

Virginia Alonso Hortale 2

\section{Introdução}

Durante as décadas 70 e 80 do século XX, discussões sobre políticas de saúde se voltam para questões como extensão de cobertura dos serviços, reconhecimento do direito à saúde e a responsabilidade da sociedade em garantir os cuidados básicos. Em 1988, a Constituição Federal estabeleceu as bases técnicas e jurídicas sobre as quais se implantou o Sistema Único de Saúde (SUS), cujo princípio fundamental é a atenção à saúde enquanto direito de cidadania, com universalidade de acesso a todos os níveis do sistema 1.

Mendes 2 sugere que a construção do SUS deve constituir-se num processo social de mudanças nas práticas sanitárias, referenciado na concepção ampliada do processo saúde/enfermidade e no paradigma assistencial da promoção da saúde. Paim ${ }^{3}$ adverte que poderá ser mantido o modelo médico assistencial-privatista, no âmbito do SUS, na medida em que se institucionalizem políticas e práticas sociais, reprodutoras de interesses econômicos e políticos de grupos profissionais, empresas, corporações e elites políticas, distanciados dos interesses e necessidades da maioria da população.

Os anos 90 são marcados pela crise econômica e fiscal do país, e pela busca de alternativas que possibilitem a superação dos limites dos modelos de saúde vigentes. São implementados programas, ações regulatórias e novas 
modalidades de alocação de recursos, com objetivo de aumentar os níveis de eqüidade e eficácia do SUS. Neste contexto são implantados o Programa de Agente Comunitário de Saúde (PACS), em 1991, e Programa Saúde da Família (PSF), em 1994.

A proposta "Saúde da Família”, estratégia político-governamental para a mudança do modelo de atenção à saúde no contexto do SUS, aponta para modificações importantes, é marcada por diferentes orientações políticas e ideológicas, o que desencadeia interpretações e posicionamentos de autores a respeito das dimensões e alcance do PSF. Uns argumentam favoravelmente quanto à operacionalização da atenção primária em saúde a partir do PSF, enquanto outros mostram o risco de, mesmo com o PSF, ocorrer a permanência do modelo tradicional de atenção à saúde.

Mendes 4 se refere à estratégia de saúde da família como parte das propostas inovadoras com vistas à formulação de novas práticas de saúde. Consiste num paradigma da produção social da saúde, por intermédio do desenvolvimento de ações direcionadas às famílias e à comunidade, de forma contínua, personalizada e ativa. Enfatiza a promoção e a prevenção, não se descuida do aspecto curativo reabilitador; com alta resolubilidade, baixos custos diretos e indiretos, sejam econômicos e sociais e privilegia a intersetorialidade.

Misoczky 5 faz considerações críticas, ao afirmar que se trata de um modelo de atenção voltado para a família dos excluídos, que não atende às necessidades da população, não valoriza os trabalhadores de saúde e não viabiliza a descentralização. Convida à reflexão sobre o SUS uma vez que constata que as políticas de saúde adotadas por este têm características de continuísmo do ideário neoliberal.

Tanto Vasconcelos 6 quanto Viana \& Dal Poz 7 consideram que o PSF representa a primeira tentativa significativa de reformulação, em escala nacional, do modelo de atenção primária à saúde. Vasconcelos 6 (p. 174-5) considera que é uma proposta de grande impacto na diminuição da mortalidade: "o PSF é um alargamento da atenção primária à saúde em direção à incorporação de práticas preventivas, educativas e curativas mais próximas da vida cotidiana da população e especialmente de seus grupos mais vulneráveis". Viana \& Dal Poz 7 argumentam que o PSF é considerado uma estratégia queprivilegia as ações de promoção, proteção e recuperação da saúde dos indivíduos e da família, fornecendo à equipe do programa uma compreensão mais abrangente do processo saúde/ doença.

A XI Conferência Nacional de Saúde realizada em dezembro de 2000 discute a superação do modelo médico assistencial-privatista e a construção de um novo modelo que privilegie a promoção da saúde e a prevenção de riscos e agravos, reduza as desigualdades e resgate as dimensões éticas e culturais essenciais ao cuidado à saúde das pessoas. O ciclo gerencial que começa a se emoldurar na administração pública brasileira, com a municipalização e a descentralização das ações e programas de saúde, remete à necessidade de seu monitoramento e aponta para indagações sobre um desenho atualizado da supervisão que contemple a realidade que ora se apresenta.

A preocupação com a supervisão em saúde se fez presente nos países da América Latina antes da década de 70. Inúmeros conceitos e definições tentam explicá-la. É importante investigá-la quanto às suas origens, formas, fundamentos teóricos, finalidades, dimensões, alcance, limites e possibilidades, para melhor subsidiar a compreensão da mesma, no PSF. Com tal intenção foi realizado um estudo no PSF do Município de Teresópolis, na região serrana do Estado do Rio de Janeiro.

\section{O Programa Saúde da Família}

O PSF implantado no país, a partir de 1994, pretende reafirmar os princípios do SUS, para isso, fundamenta-se na concepção de atenção focalizada na promoção da qualidade de vida e tem como objetivo trabalhar práticas de saúde que gerem integração entre as ações individuais e coletivas. Os pressupostos que devem nortear a organização das práticas de saúde voltadas à família, tais como o reconhecimento da saúde como direito de cidadania, eleição da família e seu espaço social como núcleo básico de abordagem, prestação de atenção integral, humanização das práticas de saúde, participação comunitária, são parte de uma estratégia primordial para induz mudanças tanto pela interferência sobre a dinâmica do mercado de trabalho em saúde, quanto pela reestruturação do processo de trabalho. Busca introduzir a lógica da efetividade para as formas de remuneração e o manejo racional de tecnologia. O desenvolvimento dessas práticas obriga que os profissionais envolvidos nas mesmas tenham visão 
integral do sujeito, da família e da comunidade, e estabeleçam novas relações entre estes atores 6,8

O profissional da equipe do PSF, segundo normas do Ministério da Saúde, precisa ser capaz de atuar com criatividade e senso crítico, mediante uma prática humanizada, competente que envolva ações de promoção, prevenção, recuperação e reabilitação. Deve ser capaz de planejar, organizar, desenvolver e avaliar ações que respondam às necessidades da comunidade, articulando os diversos setores envolvidos na Promoção da Saúde 1 .

Nessa perspectiva, é necessário o redirecionamento do processo de trabalho devido às novas competências exigidas do trabalhador de saúde. Inicia-se, então, a discussão sobre a formação de recursos humanos para o SUS, em particular o profissional que atua no PSF e o papel que a supervisão deve assumir.

\section{Supervisão: super-visão ou com-visão}

O termo supervisão se origina das palavras latinas "super" que significa "sobre" e "video" que eqüivale a "eu vejo". O emprego literal destes termos pode ser interpretado como inspeção; contudo, de sua evolução resultaram novas concepções. Na visão tradicional, supervisão significa "visão sobre" o objeto do trabalho realizado por outro; define, comanda, impõe, inspeciona, fiscaliza; estabelece uma relação assimétrica entre o supervisor e o supervisionado, é imposta e autoritária; faz parte de um modelo de gestão vertical (cobrança/auditoria). A visão moderna associa controle e educação, propõe uma relação entre parceiros, identifica práticas e instrumentos de atuação conjunta sobre o objeto de trabalho e é denominada "convisão" (termo cunhado por Roberto Nogueira e utilizado por Nunes \& Barreto 9), que significa gestão "co-laborativa” ou construção conjunta. É necessário avaliar qual o modelo que mais se aproxima das singularidades e exigências do PSF.

Quando analisada como parte integrante do sistema de saúde, a supervisão apresenta-se como elemento viabilizador da política de saúde, à proporção que repassa conceitos, redefine procedimentos, dá mobilidade entre os vários níveis do sistema e orienta a execução dos serviços. Assume uma dimensão política à medida que interpreta os interesses dos níveis periféricos, e procura reforçar o processo de descentralização. Embora se instrumentalize valendo-se de conteúdos técnico-administrativos, definidos em consonância com os objetivos da políti- ca de saúde, a supervisão deve rever tais conteúdos com base nas necessidades reais, face ao caráter dinâmico da realidade de saúde enquanto parte da estrutura social e política.

Neste estudo, a supervisão é discutida na perspectiva das características contemporâneas das organizações de saúde, coerente com a proposta do PSF e com a nova forma de planejar e agir em saúde que propicie aos atores envolvidos suplantarem a alienação, conscientizarem-se, e poderem se envolver no processo de trabalho, no processo de supervisão compartilhada, no processo de "convisão".

\section{O PSF de Teresópolis}

O Município de Teresópolis, onde o estudo foi realizado, é localizado na região serrana do Estado do Rio de Janeiro. A estimativa da população do município é de 120.079 habitantes, com $83 \%$ da população residentes na área urbana e $17 \%$ na área rural. Cerca de $15 \%$ destes vivem em áreas carentes, com grandes concentrações populacionais e precariedade de serviços públicos. O processo de pauperização do município tem se intensificado nos últimos anos e pode ser caracterizado pelo elevado índice de favelização, considerado o primeiro do Estado do Rio de Janeiro 10.

O PSF foi implantado no município em agosto de 1999, após convênio firmado entre a Prefeitura Municipal, pela da Secretaria Municipal de Saúde, e a Fundação Educacional Serra dos Órgãos (FESO), instituição de ensino superior. A FESO se incumbe da capacitação de profissionais para atuação no PSF em alguns municípios do Rio de Janeiro, pelo Pólo de Capacitação, Formação e Educação Permanente em Saúde da Família.

O programa é formado por nove unidades e 11 equipes de saúde da família. Cada equipe é composta por um médico, um enfermeiro, um ou dois auxiliares de enfermagem e quatro a seis agentes comunitários de saúde. Estudantes de medicina, odontologia e enfermagem da FESO realizam estágio supervisionado nas unidades. É coordenado por uma enfermeira e conta com equipe de supervisores técnicos das diversas áreas (gineco-obstetrícia, pediatria, clínica, nutrição, psicologia, enfermagem), que após receberem capacitação para o exercício da função, dão sustentabilidade ao processo de educação continuada e permanente destas equipes. Os supervisores realizam tanto as supervisões gerais (monitoramento das ações de saúde relativas à implementação do PSF) como as supervisões técnico-específicas. 
As equipes desenvolvem várias atividades internas e externas às unidades, com o objetivo de promover, prevenir e dar assistência à população a ela adstrita. Após cadastramento das famílias que vivem em sua área de abrangência, identificam a população e a vinculam à unidade de saúde. Realizam diagnóstico dos problemas de saúde das famílias para o planejamento das ações. Acompanham os grupos mais vulneráveis ao adoecimento e à morte e os portadores de doenças crônico-degenerativas, por meio das ações programadas, com o objetivo de minimizar e reduzir possíveis riscos. Prestam assistência integral na unidade de saúde ou no domicílio, com consulta médica e/ou de enfermagem, e de visitas domiciliares. São desenvolvidas atividades de educação em saúde - palestras, campanhas, reuniões de grupos (hipertensos, diabéticos, gestantes, planejamento familiar, pré-natal, puericultura, adolescentes), visitas domiciliares, vacinação, busca ativa de casos relacionados aos grupos de risco, reuniões com a comunidade, mobilização comunitária.

Quando é feita a referência de um usuário para realizar exames ou tratamento especializado, é responsabilidade da equipe dar seguimento ao caso após o seu retorno. Cada equipe atende em média 3.450 pessoas. A população acompanhada representa $29,5 \%$ da população do município.

\section{Supervisão no PSF de Teresópolis}

O documento oficial do PSF de Teresópolis estabelece que a supervisão tem como objetivo geral dar suporte técnico às equipes com a finalidade de garantir que a implantação e manutenção do programa se façam totalmente.

Seus objetivos específicos são: contribuir para a capacitação de recursos humanos, possibilitando o aperfeiçoamento profissional e a melhoria da capacidade resolutiva das equipes de saúde pela educação continuada e permanente; participar no processo de criação de vínculos de responsabilidade com a população assistida; proporcionar às equipes garantia de desenvolvimento de um trabalho pautado em princípios éticos, fornecer-lhes meios para utilização racional dos recursos técnicos disponíveis; apoiar a coordenação do programa a fim de garantir as mudanças do modelo de atenção à saúde.

Cabe ao supervisor realizar visitas semanais às unidades de saúde da família conforme programação mensal; avaliar assiduidade, pontualidade, compromisso e co-responsabilidade das equipes em relação ao trabalho desenvolvido; participar das reuniões de equipe quando solicitado; operacionalizar o processo de educação continuada e permanente; propor ações capazes de dar suporte e apoio às equipes e indicar modelos de avaliação do trabalho realizado; participar das reuniões de supervisores; criticar e avaliar as ações propostas pela coordenação.

Nos primeiros 18 meses de funcionamento do programa, período no qual este estudo foi realizado, os supervisores efetuaram visitas regulares (supervisões técnico-operacionais) às nove unidades de saúde da família para observar as atividades e fazer contato com as equipes. Por demanda das unidades, os supervisores especialistas também realizaram visitas. Ainda durante a fase de implantação do programa, um supervisor permaneceu durante dois meses em uma só unidade, acompanhando todas as ações desenvolvidas.

As principais dificuldades detectadas pela análise dos relatórios dos supervisores foram: administrativas (organização da unidade - arquivo, horário e atividades que operacionalizam o programa - grupos, visitas domiciliares, organização dos agentes de saúde) e interpessoais (relação equipe-paciente, equipe entre si, equipe-supervisão, agentes de saúde-comunidade-equipe).

A complexidade do programa exige que o supervisor tenha clareza de suas diferentes dimensões: interesses e visões sobre modelos de saúde, especialmente do PSF; visões da equipe a respeito do processo de adoecer; compreensão da dinâmica das relações interpessoais entre a equipe e a comunidade; inserção do agente comunitário na equipe; relações entre a coordenação do programa e a equipe de supervisão; características das supervisões técnicas específicas e a relação entre os supervisores.

A supervisão deve ser entendida como um processo amplo, complexo, educativo e contínuo, que inclui exame, avaliação, assessoria, informação e intercâmbio dinâmico de conhecimentos e experiências; tarefa que envolve a intersubjetividade e, portanto, múltiplas formas de perceber, sentir, reagir e interpretar situações.

Investigar a supervisão pode contribuir para o entendimento dos processos de gestão, levar a um equacionamento de aspectos críticos do programa e possibilitar a mudança de modelo de atenção à saúde. Neste estudo discutimos o processo de supervisão, explorando o caminho da participação como alternativa à supervisão enquanto processo unilateral e autoritário. Sua finalidade foi a de fornecer subsí- 
dios para a compreensão da supervisão em saúde e especificamente no PSF, para tal foram analisadas as características da supervisão do PSF de Teresópolis.

\section{Método}

A pesquisa, de natureza qualitativa, focaliza a supervisão, toma como princípio metodológico o estudo de caso, analisa uma unidade específica - o PSF de Teresópolis. Foi realizada mediante autorização da coordenação do Programa e com o consentimento esclarecido dos participantes.

Os procedimentos utilizados neste estudo foram de três tipos: documental, observação livre e entrevistas. Para o primeiro, foram pesquisados relatórios oficiais de supervisão, atas das reuniões de supervisores, registros de arquivo, regulamentos, pareceres, decretos, diretrizes, propostas e resoluções. A livre observação das ações foi utilizada para conhecer detalhes das circunstâncias nas quais as supervisões acontecem, o que propicia identificar componentes subjetivos intrínsecos à dinâmica das ações, e enriquecer a análise do processo.

Foram realizadas 19 entrevistas semi-estruturadas com supervisores e membros das equipes fundamentadas num roteiro específico, com base em Ludke 11, centradas na linguagem dos profissionais. O objetivo foi compreender como os primeiros se vêem como tal e como concebem o processo de supervisão. Com os membros das equipes, o intuito foi o de compreender como estes vivenciam o papel de supervisionados e como percebem a supervisão. Foram observados os sinais não verbais (gestos e expressões) - “atenção flutuante" 12 na tentativa de captar sinalizações de insegurança, de hesitações ou de quaisquer outras manifestações. Das 19 entrevistas, cinco foram efetuadas com os supervisores: duas enfermeiras, uma das quais acumula a função de supervisão com a de coordenação do programa, uma nutricionista, uma pediatra e uma psicóloga. Dos supervisionados, foram entrevistados seis médicos, quatro enfermeiras, um auxiliar de enfermagem e três agentes comunitários de saúde.

$\mathrm{Na}$ análise das entrevistas, o objetivo foi o de perceber as reações dos entrevistados em relação ao entrevistador e ao tema proposto, encontrar uma ordenação entre o discurso dos entrevistados e o tema da pesquisa, fazer comparação entre estes discursos buscando-se pontos convergentes e divergentes e a forma de articulá-los ao objeto. Isso permitiu observar as atitudes, valores, crenças e tendências em rela- ção ao objeto. A análise das respostas seguiu um modelo de interpretação do discurso inspirado na etnometodologia de Coulon 13 . Esta se caracteriza por refinar as categorias analíticas na interação com os dados, na impregnação progressiva do pesquisador pela forma e pelos conteúdos do discurso, retarda-se de propósito a interpretação, deixa-se para um segundo momento o papel da inferência, que muitas vezes é precipitado.

Em um primeiro momento, a hierarquização e a categorização foram feitas de forma horizontal, isto é, para cada pergunta existente na entrevista, foram hierarquizadas as respostas de todos os informantes. Em um segundo momento, analisou-se separadamente, de forma vertical, o discurso de cada informante em relação ao grupo de perguntas correspondentes à variável analisada, para, a partir daí, identificar as divergências e as convergências existentes. As variáveis ficaram assim definidas:

1) Padrão da supervisão - construída pelas características das supervisões realizadas, das situações nas quais as supervisões foram solicitadas, da identificação dos componentes que os entrevistados consideram prioritários na supervisão e da descrição das atividades de supervisão necessárias para alcançar os objetivos do PSF;

2) Processo de supervisão - construída pela ótica dos entrevistados, a respeito de como se deu a supervisão no PSF de Teresópolis, desde a implantação do programa, em agosto de 1999, até o momento da realização das entrevistas, em outubro e novembro de 2000. Foram investigados valores, necessidades e ideologias dos informantes; as diferentes situações e demandas nas quais as supervisões aconteceram e a forma como se desenvolveram: controladora ou compartilhada.

3) Fatores subjetivos envolvidos na supervisão - foi utilizado o conteúdo das entrevistas para analisar aspectos centrados nos sujeitos tais como: diferentes formas de perceber, sentir, reagir e interpretar situações nas quais as supervisões se realizaram. Esta variável teve ainda como objetivo investigar a rede de relações, ações e reações, conflitos e dificuldades dos sujeitos. Estes aspectos foram detectados com base nas observações livres realizadas nos momentos das supervisões.

4) Perfil do supervisor - objetivou-se traçar o perfil do supervisor do PSF pelo exame das competências, habilidades, atributos e postura que este profissional deve possuir. Contou-se com as informações dos supervisores a respeito das percepções que têm do próprio exercício da função. 
As quatro variáveis foram utilizadas para observação da importância da supervisão no processo de implantação e implementação do PSF.

A análise final estruturou-se na triangulação das informações, o que permitiu grande amplitude na descrição, explicação e compreensão do objeto de estudo, e possibilitou o cruzamento de múltiplos pontos de vista. Essa técnica aborda os processos centrados no sujeito (informantes, suas percepções, comportamentos e ações), os elementos produzidos pelo meio (resultados da supervisão verificados em documentos, e atas de reuniões), e o contexto sócioeconômico e cultural no qual acontecem estas interações (relações estabelecidas tendo o modo capitalista de produção como base).

\section{Discussão dos resultados}

\section{Padrão da supervisão}

A supervisão realizada no PSF de Teresópolis apresenta-se sob diferentes modalidades. Não cumpre um padrão previamente definido, assume características diferenciadas, delineia-se de acordo com a demanda das equipes. As supervisões técnico-operacionais ocorrem em dois planos: no geral e no específico; o geral se caracteriza pelo monitoramento das ações de saúde na perspectiva do modelo do PSF e pelo acompanhamento de todas as atividades da unidade, observado por uma das falas: “(...) $a$ gente trabalha com a organização do serviço, com o planejamento das ações e com a avaliação dos resultados. O supervisor é aquele que trabalha em várias questões, que podem ser técnico-operacionais, administrativas, na verdade questões gerais da Unidade".

No plano específico, as supervisões são realizadas em função das especialidades, supervisões de caráter funcional. $\mathrm{O}$ aspecto administrativo é contemplado pelas supervisões, nas quais são averiguados o cumprimento de horário e assiduidade dos profissionais. Em relação à supervisão técnico-pedagógica, como foi nomeada pelos supervisionados, percebe-se uma distorção na sua implementação, segundo os entrevistados, " pois ela deveria ser mais presente e se constituir num instrumento privilegiado de aprendizado". E em um instrumento de educação continuada e permanente, como propõe o documento oficial da supervisão do PSF de Teresópolis.

Foram pontuados como componentes prioritários da supervisão: apoio, orientação, acompanhamento e instrumento de aprendizagem.

\section{Processo de supervisão}

Foram detectados aspectos pouco claros quanto ao processo de supervisão na fase de implantação do programa. Não havia delimitação clara o suficiente quanto às supervisões técnicas gerais e específicas. Estas, ainda que requisitadas em função de uma demanda específica, assumiam caráter geral; uma vez satisfeita a demanda técnica específica, outras situações da unidade eram supervisionadas com o mesmo supervisor.

As visitas da supervisão às unidades, acontecem com ou sem solicitação das equipes e, quando realizadas sem solicitação, eram percebidas como fiscalização: "Muitas equipes vêem o supervisor como um fiscal. No início, isso foi motivo de muita controvérsia, as equipes ficam muito com 'o pé atrás', as equipes se sentiam acuadas cada vez que o supervisor vinha (...). Um ponto positivo que teve no período de um ano e pouco do PSF é que as equipes passaram a ver o supervisor como uma ajuda, como um apoio para elas e não como um fiscal".

$\mathrm{O}$ registro das entrevistas e das observações realizadas durante as supervisões mostrou que cada equipe tem dinâmica e demanda próprias em relação à supervisão. $\mathrm{O}$ que aponta para o fato de que a supervisão é um processo individualizado e pessoal, no qual estão imbricadas características e necessidades específicas do supervisor e do supervisionado (equipe).

\section{Fatores subjetivos envolvidos na supervisão}

Na análise das entrevistas, pôde-se constatar que o processo de supervisão, longe de ser um processo objetivo que envolve questões de cumprimento de regras e normas, direcionamentos e determinações, é um processo no qual estão incluídos aspectos subjetivos. Formas diferentes de solicitar supervisões, de avaliar suas necessidades, de enxergar a função e a importância desta, de conceber o papel dos supervisores e as formas como os supervisionados se percebem como tal. Inúmeras percepções, sentimentos, interpretações, crenças e desejos dos supervisores e supervisionados, reunidos e articulados fazem parte deste processo.

Os fatores subjetivos envolvidos tanto no trabalho das equipes como no processo de supervisão foi uma tônica na fala dos supervisores e dos supervisionados. Os conflitos interpessoais entre os membros das equipes e a falta de coesão destas são um aspecto pregnante tanto nas falas dos entrevistados como na observação do dia a dia das unidades; constituindo-se foco prioritário da supervisão. A fala de 
um dos informantes explicita a situação: “ $A$ grande dificuldade hoje das equipes é conseguir trabalhar de uma forma coesa, integrada, e até pelos diferentes tipos de personalidade...".

Outro aspecto evidenciado nas falas foi a construção de uma relação de dependência entre a supervisão e as equipes (percebido no período inicial, quando os supervisores permaneciam durante dois meses na mesma Unidade). Mas, no momento em que os supervisionados confiam na supervisão e em seu trabalho, ficam mais independentes, como se observa na fala deste supervisor: "Eles esperavam da gente que ficássemos todo o tempo ali, dando apoio. Seríamos uma bengala mesmo. Com o tempo estão vendo que podem caminhar sozinhos".

O fato de a supervisão ser solicitada pela equipe ou oferecida pelo supervisor perpassa a fala dos entrevistados, o que reflete características particulares. Observou-se que uma equipe mais dependente considera sempre que se a supervisão "não aparece”, está abandonandoa. Ao contrário, uma equipe mais autônoma, se a supervisão "aparece sem aviso" vive esta situação como um controle. Há também as equipes auto-suficientes que dizem que está sempre tudo bem, sem problemas e criam, com esse comportamento, uma barreira entre elas e a supervisão. Os membros da equipe criam entre si uma aliança tão forte que um elemento externo (supervisão, neste caso) é excluído. Percebem-se, ainda, supervisores com características pessoais de flexibilidade ou rigidez, que fazem "parcerias" com determinadas equipes.

Os fatores subjetivos perpassam todo o processo de supervisão, seja na questão das relações interpessoais e coesão das equipes, na percepção dos aspectos de controle e fiscalização e no processo de trabalho. Um aspecto a ser ressaltado é a função de suporte da supervisão. Espera-se que a supervisão trabalhe com o fito de elaborar, junto com as equipes, as situações de conflito, já que estas podem se tornar impeditivas para realização do trabalho. Se forem vivenciadas sem a oportunidade de reflexão e de trocas entre supervisores e supervisionados, possivelmente se constituirão em fatores geradores de ansiedade, de desintegração da equipe e ineficiência no processo de trabalho em ambos os lados. A função de suporte da supervisão aparece de forma marcante, como se pode observar na seguinte fala: “A supervisão tira um pouquinho de nossa ansiedade, a gente fica ansiosa para resolver as coisas e nem sempre a gente consegue resolver da melhor maneira possível, é bom esse apoio no nosso dia a dia. Precisamos de acompanhamento".

\section{Perfil do supervisor}

Na tentativa de se "traçar" um perfil do supervisor do PSF, foram abordadas questões acerca da postura desejável de um supervisor. Uma das falas resume esse perfil: "é preciso que o supervisor tenha um perfil, que ele tenha uma ideologia, que ele acredite na mudança de paradigma da saúde, que tenha conhecimento em políticas públicas de saúde, tenha uma inserção na saúde coletiva".

Segundo os entrevistados, para exercer sua função, o supervisor não pode ter uma postura recriminatória de caráter punitivo, mas estabelecer relação horizontal, buscar estratégias para indicar e sugerir caminhos, deve saber dialogar e ter bom senso. Deve ter um olhar integrador e não fiscalizador. Estas idéias estão representadas nesta fala: "quanto à postura, eu acho que o supervisor não tem que se colocar como um Deus...chegou na Unidade ele é o todo poderoso. Tem que ter uma conduta diferente(...)ele não pode chegar com intuito de punição(...)tem que ver uma estratégia de mostrar para a pessoa sem 'ofender'. Essa postura é importante: de não recriminar, não penalizar $e$ não expor o supervisionado".

Dentro da concepção da "convisão", o perfil do supervisor (convisor) deve ser o de agente da produção de conhecimento, aquele que não só induz às duvidas, mas que junto ao grupo tenta encontrar soluções. Todavia, aspectos contraditórios são registrados nos relatos dos entrevistados que vêem o supervisor não apenas como integrador, e sim como fiscalizador e controlador. Um dos entrevistados sugeriu que o supervisor tivesse a função de policiamento.

Um aspecto a ser destacado é o da neutralidade do supervisor, evidenciado pelos entrevistados. Essa concepção sugere um distanciamento suficiente do supervisor em relação ao processo de supervisão, para que possa perceber, sem envolvimento, a situação a ser supervisionada. A “convisão" marca o oposto, a implicação no processo, por parte do convisor, é fundamental para que a supervisão se realize.

\section{Considerações finais}

A partir das reformulações do sistema de saúde, o novo ciclo descentralizado impõe mudanças no processo de gestão: o comprometimento com a coletividade é cada vez mais exigido. Mudam as relações interpessoais, o processo de trabalho, as estratégias de gestão.

Os profissionais que atuam no PSF se graduaram segundo um paradigma curativo e frag- 
mentado da saúde, em que são valorizadas as especialidades e não a compreensão global do ser humano e do processo do adoecer. É exigido deste profissional um conhecimento técnico generalista não adquirido em sua formação. Há necessidade de redirecionar a formação dos profissionais de saúde frente às práticas de saúde contemporâneas. Esta realidade vem reafirmar a ação pedagógica da supervisão como ferramenta da educação continuada e permanente. Não por intermédio da supervisão pedagógica tradicional, reprodutora de conteúdos e conceitos prontos, mas uma supervisão que atue como instrumento de reflexão, mudanças e transformações, que se constitua no instrumento catalisador destas transformações, realizando-se a prática da ação-reflexão-ação.

Para tal retornamos ao conceito de supervisão que tem suas raízes históricas ancoradas numa relação vertical de poder e autoridade, por isso não mais suficiente para subsidiar as necessidades que emergem. Esta deverá dar lugar à supervisão compartilhada, consciente, convivida, a "convisão", que é o veículo da participação. Nesta perspectiva, "convisores” e "convisionados" juntos, constroem o conhecimento, partilham dúvidas e buscam a resolução dos problemas; atingem a conscientização, que, na concepção de Freire 14,15, é diferente da tomada de consciência. Esta tem caráter limitado, não crítico e se aproxima da idéia de supervisão (conhecimento vindo de fora, que toma a consciência). Já a conscientização supõe um desenvolvimento crítico da tomada de consciência e permite não só desvelar a realidade, incidir no nível do conhecimento, como também criar uma postura de curiosidade epistemológica.

A educação problematizadora envolve um processo ativo de resolução de problemas, permite a conscientização e a transformação de situações. Assim, a "convisão" pode se desenvolver e atingir objetivos amplos: supervisão técnica, mudanças nas relações de trabalho que permitam suplantar a alienação, mudanças no modelo de atenção, práticas de participação comunitária (possibilitar o exercício do controle social).

A reestruturação do modelo de atenção modifica os paradigmas e as concepções a respeito do ter saúde e do adoecer, os objetivos e os focos das ações, também o "fazer" em saúde, transformando atitudes, posturas e comportamentos. Surgem dificuldades técnicas, administrativo-gerenciais, associadas às dificuldades emocionais. A angústia gerada pelas transformações e pela necessidade de enfrentamento da nova realidade deve ser compreendida e "suportada”. Os sentimentos de impotência de- correntes do confronto com situações de extrema pobreza e miséria humanas, com as quais muitos dos profissionais atuantes no PSF, anteriormente protegidos pelas paredes dos hospitais ou de consultórios, não entravam em contato, agora fazem parte de seu cotidiano.

Entraves de natureza subjetiva se manifestam pela via dos conflitos interpessoais e prejudicam a realização do trabalho em equipe, ponto primordial do PSF. Os relatos dos entrevistados confirmam a necessidade da supervisão trabalhar as relações de equipe, fortalecer os vínculos entre seus membros, para que os princípios do PSF se concretizem.

Frente a este cenário, a supervisão enquanto instrumento gerencial e técnico-pedagógico é insuficiente para contemplar a complexidade que a reestruturação sanitária ora necessita. $\mathrm{O}$ aspecto "suportivo" da supervisão/convisão fornece grande contribuição afim de que dificuldades de variadas naturezas sejam trabalhadas, entendidas e elaboradas.

A natureza humana se caracteriza por estabelecer vínculos com seus semelhantes, o bebê, frágil e imaturo, precisa de alguém que lhe dispense cuidados. A família é formada fundamentando-se nesta necessidade primeira de cuidar e ser cuidado. Campos 16 mostra que não só o bebê imprescinde deste cuidado. $\mathrm{O}$ adulto precisa do outro para sentir-se amado, estimado, valorizado, compreendido, cuidado; precisa de um suporte. Este conceito foi desenvolvido por Caplan \& Killelea 17, quando analisaram os vários tipos de suporte que fazem parte da coletividade humana. Demonstraram que os sistemas de suporte permitem a construção de vínculos duradouros fundamentais para a manutenção da integridade física e psicológica do indivíduo.

O conceito de suporte social foi discutido por Sidney Coob também em 1976 e sintetizado por Campos 16 (p. 117), trata-se de uma "forma de relacionamento grupal na qual prevalecem as trocas afetivas, os cuidados mútuos e a comunicação franca e precisa entre as pessoas. A rede grupal constituída é solidária, tem papéis definidos e ocorre de maneira constante, continuada. A resultante é um sentimento de coesão e de apoio que empresta ao grupo subsídios para o enfrentamento da realidade".

A supervisão exercida como suporte faz com que as equipes, ao se sentirem cuidadas e compreendidas, apresentem maior possibilidade de compartilhar afetividade e cuidados mútuos, adquiram meios saudáveis de entendimento das dificuldades e limitações, de resolução de conflitos internos e, mais estruturadas, atendam de modo eficaz a seus pacientes. Suporte gera 
suporte; quem é bem cuidado constrói a capacidade de ser um bom cuidador. Uma equipe que recebe suporte transmite sua capacidade de suporte aos que necessitam de seus cuidados.

A equipe de supervisores, ao exercer função nova para ela, é investida de responsabilidade e poder, prescinde, também, de maiores cuidados. As reuniões semanais dos supervisores com a coordenação funcionam como oportunidade de troca, apoio, suporte. Há uma troca de suportes entre a supervisão e a coordenação do programa.

Este estudo vem mostrar a importância de operacionalizar a função de suporte da supervisão. Sugere-se que esta se realize formando um tripé: - gerencial/administrativo - técnico/pedagógico - "suportivo". A estratégia da problematização deve ser utilizada como impulsionadora da reflexão, da criatividade, da possibilidade de resolução de problemas e do desenvolvimento da prática da co-laboração.
A supervisão, na perspectiva da "convisão", é um processo em construção, traz possibilidades de crescimento profissional, desenvolvimento da liberdade e autonomia, de reflexão das práticas e questionamento dos modelos de atenção. Carrega seus limites, a inevitável ação fiscalizadora, e a possibilidade de estabelecimento de dependência dos supervisionados pela supervisão. É importante enxergar que o limite não é um impedimento definitivo, mas uma possibilidade de transformação futura; a possibilidade não é algo seguro e concluído, também tem limites e pode ser reinventada.

Este trabalho pretendeu esboçar uma reinterpretação da supervisão em saúde. Espera-se que esta possa contribuir para o aprimoramento e sustentação de um programa que atenda às necessidades de saúde da população brasileira; ainda tão marcada pelas desigualdades sociais, e que o PSF seja uma real proposta de mudança, não mais uma tentativa política de escamotear os problemas de saúde pública.

\section{Resumo}

O estudo, de natureza qualitativa, utiliza como estratégia metodológica o estudo de caso para discutir a supervisão no Programa Saúde da Família (PSF) do Município de Teresópolis, Estado do Rio de Janeiro. A supervisão é um instrumento de gestão de programas de saúde,motivo pelo qual objetivou-se analisá-la com base nos seguintes objetivos:descrever as características e o padrão de funcionamento da supervisão, identificar fatores subjetivos intrínsecos à dinâmica do processo, delinear o perfil do supervisor do PSF e refletir sobre a supervisão como fator essencial de implantação e implementação do programa. Foram pesquisados documentos, feita observação livre e entrevistados supervisores e membros das equipes que compõem o PSF de Teresópolis,para identificar percepções, atitudes, valores e tendências destes em relação à supervisão. O estudo permitiu discutir a supervisão participativa, baseada nas relações horizontais entre os participantes. Esta deve refletir sobre as práticas de saúde, estimular a autonomia dos atores envolvidos e contribuir para a sustentação de programas compativeis com a mudança do modelo de atenção brasileiro.

Programa Saúde da Família; Supervisão; Cuidados de Saúde

\section{Colaboradores}

C. C. L. Reis fez o desenho da metodologia, desenvolveu o trabalho de campo e fez a análise dos resultados. V. A. Hortale auxiliou na sistematização do desenho da metodologia e da discussão dos resultados.

\section{Agradecimentos}

Agradecemos ao Pólo de Capacitação, à coordenação e a toda equipe do PSF de Teresópolis pela seriedade com que conduzem o programa e pelo incentivo e confiança ao permitirem a realização desta pesquisa. 


\section{Referências}

1. Ministério da Saúde. Saúde da família: uma estratégia para a reorientação do modelo assistencial. Brasília: Secretaria de Políticas de Saúde, Departamento de Atenção Básica, Ministério da Saúde; 1998.

2. Mendes EV. Distrito sanitário - o processo social de mudança das práticas sanitárias do SUS. São Paulo: Editora Hucitec/Rio de Janeiro: ABRASCO; 1993.

3. Paim JS. A reforma sanitária e os modelos assistenciais. In: Rouquayrol MZ, organizador. Epidemiologia e saúde. 4a Ed. Rio de Janeiro: Medsi; 1994. p. 455-66.

4. Mendes EV. Uma agenda para a saúde. São Paulo: Editora Hucitec; 1996.

5. Misoczky MC. A medicina da família, os ouvidos do príncipe e os compromissos com o SUS. Saúde em Debate 1994; 42:40-4.

6. Vasconcelos EM. Educação popular e a atenção à saúde da família. São Paulo: Editora Hucitec; 1999.

7. Viana ALD, Dal Poz MR. A reforma do sistema de saúde no Brasil e o Programa de Saúde da Família. Physis 1998; 8:11-48.

8. Cordeiro H. O PSF como estratégia de mudança do modelo assistencial do SUS. In: Ministério da Saúde, organizador. Saúde da família - construindo um novo modelo. Brasília: Ministério da Saúde; 1996. (Caderno de Saúde da Família, no 1).
9. Nunes TCM, Barreto CMG. Uma proposta de supervisão para a Diretoria de Vigilância e Controle Sanitário (DIVISA). Salvador: Secretaria de Políticas Públicas do Estado, Governo do Estado da Bahia; 1999.

10. Faculdades Unificadas Serra dos Órgãos. Começar de novo: pensando e repensando o PSF Teresópolis. Teresópolis: Faculdades Unificadas Serra dos Órgãos; 2001.

11. Ludke M. Pesquisa em educação: abordagens qualitativas. São Paulo: EPU; 1986.

12. Thiollent M. Metodologia da pesquisa-ação. São Paulo: Cortez; 1988.

13. Coulon A. Etnometodologia. Petrópolis: Vozes; 1995.

14. Freire P. Pedagogia da autonomia: saberes necessários à prática educativa. São Paulo: Paz e Terra; 1996.

15. Freire P. Pedagogia do oprimido. Rio de Janeiro: Paz e Terra; 1978.

16. Campos ER. Grupos de suporte. In: Mello Filho J, organizador. Grupo e corpo: psicoterapia de grupo com pacientes somáticos. Porto Alegre: Artmed; 2000. p. 117-30.

17. Caplan G, Kililea M. Support systems and mutual help. New York: Grune \& Stratton; 1976.

Recebido em $07 /$ Jan $/ 2003$

Versão final reapresentada em 25/Ago/2003 Aprovado em 23/Out/2003 